\title{
PLASMA PHOSPHATASE IN RICKETS AND OTHER DISORDERS OF GROWTH
}

\author{
BY \\ JEAN SMITH, M.D., M.R.C.P., \\ Assistant Physician to the Infants Hospital, and the Princess Louise Hospital \\ for Children, London.
}

Investigations carried out in 1931-32 revealed that the plasma phosphatase is increased in active rickets ${ }^{1}$, the degree of increase corresponding to the severity of the disease. They also showed that, whereas the serum calcium and phosphorus rapidly returned to the normal amount under treatment, the decline in the figures for phosphatase was much more gradual, normal values not being regained until the healing process was complete.

It has long been recognized that radiological proof of the presence of rickets is only obtained at a fairly advanced stage of the disease, and the present investigations were undertaken to ascertain what changes, if any, take place in the plasma phosphatase in children taking a rachitogenic diet before such radiological evidence is forthcoming, and the effect of antirachitic treatment in such cases. The method used was a modification of Kay's method as described in an earlier paper'.

The infants on whom these investigations were carried out were classed in the following groups:-

Group 1. 10 healthy breast-fed infants.

Group 2. 13 infants on artificial food with added fat-soluble vitamins.

Group 3. 16 infants with radiological evidence of rickets.

Group 4. 10 infants on rachitogenic diets.

Group 5. 15 infants with various conditions associated with cessation of growth.

All the children were seen at frequent intervals, weekly or fortnightly, and were examined for the usual signs of rickets (sweating, flabbiness, anæmia, delay in dentition, closure of fontanelle and sitting up). They were also radiographed at frequent intervals to detect any changes at the epiphyses or costochondral junctions.

Group 1.-The ages of the 10 healthy breast-fed infants in this group varied from 6 to 8 months. The average plasma phosphatase was 0.248 units, with a range of 0.2 to 0.3 units.

Group 2.-The 13 infants in this group were fed on artificial foods, but with the addition of cod-liver oil (or preparations containing vitamins $A$ and $D$ ), and orange juice. With two exceptions who were 12 and 11 months old respectively, the ages of these infants were between 4 and $8 \frac{1}{2}$ months, the average being approximately $7 \frac{1}{2}$ months. The average plasma phosphatase in this group was 0.3 units, with a range of 0.2 to 0.36 units : that is, practically the same as in the healthy breast-fed infants 
of Group 1. Of these 13 cases, 5 had been fed on condensed milk, 2 on full-cream dried milk, and 4 on humanized dried milk, and 2 on boiled cow's milk.

Group 3.-There were 16 cases of radiological rickets constituting this group. As might be expected, the age of these children was higher than that of the two previous groups. The youngest was 5 months, the oldest 2 years and 8 months, and the average age was 18 months. The plasma phosphatase ranged from 0.41 to 1.29 units, with an average figure of 0.772 units.

These results demonstrated that the plasma phosphatase of infants on artificial foods with added vitamins was approximately the same as that of healthy breast-fed infants, but was greatly increased where radiological evidence of rickets was present. It was, therefore, decided to estimate the phosphatase in a group of infants fed on rachitogenic diets before radiological signs of rickets could be recognized.

Group 4.-Ten infants on rachitogenic diets were investigated. Their ages varied from 3 to $12 \frac{1}{2}$ months, with an average of 7 months.

The feeding in these cases was as follows:-Case 1 at the age of $12 \frac{1}{2}$ months was still entirely breast fed. Cases 2, 6, 7, 8 and 10 were fed on condensed milk, either

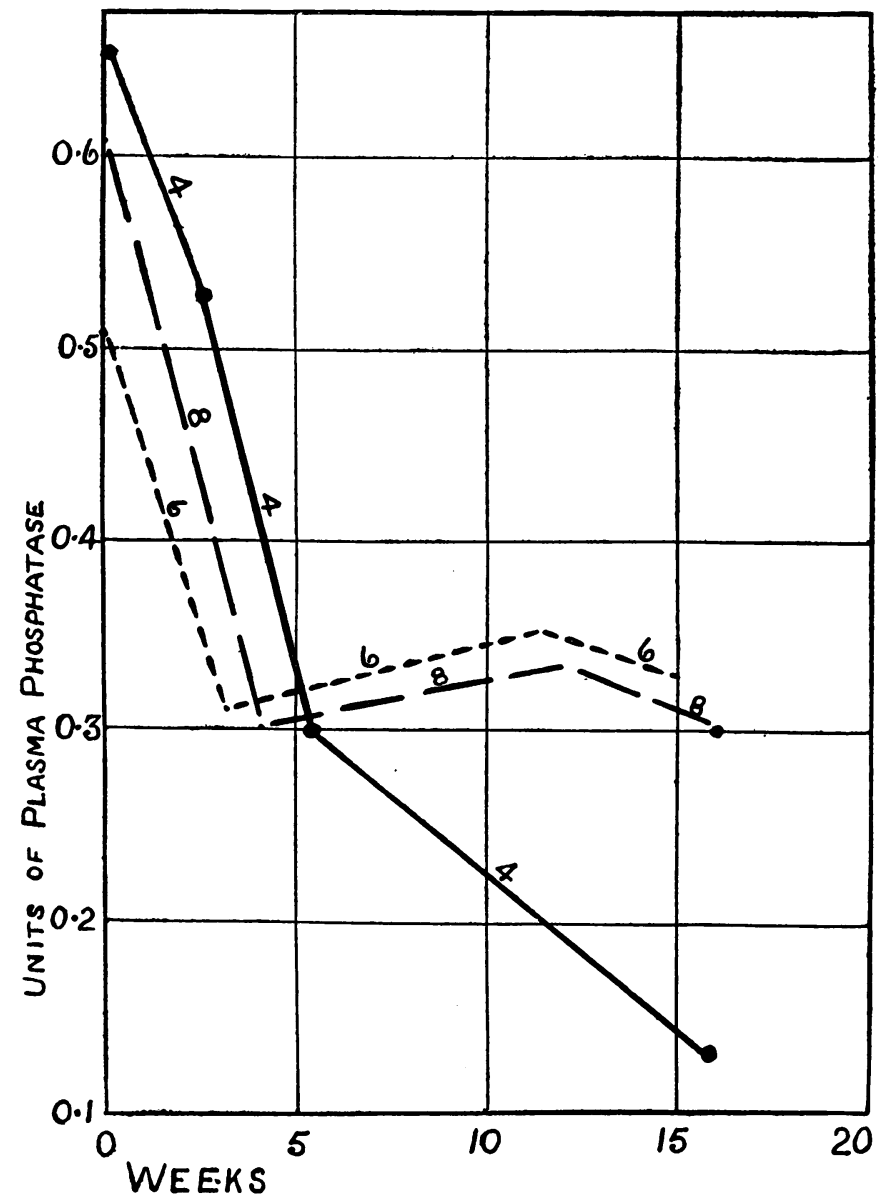

Fig. 1.-Cases 4, 6 and 8: showing abnormally high phosphatase and the fall on administration of cod-liver oil. (see Table 1). 
from birth or after very brief breast feeding. Cases 4, 5 and 9 were fed on humanized dried milk, and Case 3 on full-cream dried milk. None of these cases had received at any time additional fat-soluble vitamins in any form, although orange-juice had been given.

The average plasma phosphatase figure for this group was 0.52 units, with a range of 0.40 to 0.702 units; that is, roughly $2 \frac{1}{2}$ times the value in the average healthy breast-fed infant.

Addition of fat-soluble vitamins to rachitogenic diet (Table 1).-These investigations, therefore, appeared to prove that the average plasma phosphatase in a group of infants on rachitogenic diets was approximately $2 \frac{1}{2}$ times that of normal breast-fed infants, and nearly twice that of a group of infants receiving additional fat-soluble vitamins, the average age of all three groups being 7 to $7 \frac{1}{2}$ months.

It was therefore decided to watch the effect on the plasma phosphatase of adding fat-soluble vitamins to the rachitogenic diet of the infants in Group 4. No other change was made in the diet during the period of observation. The results of these investigations are shown in Table 1 in which it is seen that in every case the addition of fat-soluble vitamins $\mathbf{A}$ and $D$ was followed by a marked fall in phosphatase. The fall in the phosphatase was most rapid in those instances (Cases 4, 6 and 7) in which the initial values were highest: but this may be mere coincidence.

In Case 4, owing to the mother's over-anxiety, more than the prescribed dose of cod-liver oil was given, probably more than the rate of growth demanded. The result was that the plasma phosphatase fell to below normal limits (0.135 units).

In Case 3, after an initial fall, there was a temporary rise in the plasma phosphatase. This is probably to be correlated with the rapid growth which took place at this period, rendering the amount of cod-liver oil given at the time relatively inadequate. At all events, the slowing of the rate of growth after this period corresponded to a permanent fall in the phosphatase although the dose of cod-liver oil remained the same.

In three instances (Cases 2, 3 and 4) calcium gluconate was given as well as cod-liver oil, but as these did not behave differently from the other cases treated by cod-liver oil alone, their improvement cannot be attributed to the calcium gluconate.

Rachitogenic diet without fat-soluble vitamins.-As it had been found that in infants fed on a rachitogenic diet the phosphatase was increased although no radiological signs of rickets were present, and that this high figure could be reduced to normal limits by the administration of fat-soluble vitamins, it was determined to investigate the effect on the phosphatase of continuing the diet while withholding the additional vitamins (Cases 9 and 10). In both instances, as long as the child was deprived of the vitamins, the plasma phosphatase continued to rise, and in both the administration of cod-liver oil was followed by a fall of the phosphatase to within normal limits (see Table 1).

The increase in the plasma phosphatase in Case 8 was present as early as the third month, in Case 9 at four months, and in Cases 2 and 4 during 
the fifth month. These facts point to the conclusion that to prevent rickets additional fat-soluble vitamins should be given to all infants fed artificially within a few weeks of birth.

TABLE 1.

Plasma phosphatase: effect of adding fat-soluble vitamins to Rachitogenic diets.

\begin{tabular}{|c|c|c|c|}
\hline Case & Date & $\begin{array}{l}\text { Plasma } \\
\text { phosphatase } \\
\text { in units }\end{array}$ & Fat-soluble vitamins (daily doses) \\
\hline 1 & $\begin{array}{l}\text { 16.11.31. } \\
\text { 16. } 2.32 . \\
\text { 16. } 3.32 . \\
\text { 29. } 3.32 .\end{array}$ & $\begin{array}{l}0 \cdot 440 \\
0 \cdot 272 \\
0 \cdot 318 \\
0 \cdot 243\end{array}$ & $\begin{array}{ccc}\text { Cod-liver } & \text { oil, } 1 & \text { drm. } \\
\text {,, } & ,, & \text {,, } \\
,, & , & \mathbf{3} \text { drm. } \\
,, & ,, & ,\end{array}$ \\
\hline 2 & $\begin{array}{ll}\text { 8. } & 3.32 . \\
24 . & 4.32 . \\
20 . & 5.32 . \\
13 . & 6.32 .\end{array}$ & $\begin{array}{l}0 \cdot 42 \\
0 \cdot 40 \\
0 \cdot 381 \\
0 \cdot 336\end{array}$ & $\begin{array}{cccc}\text { Cod-liver } & \text { oil, } & \mathbf{1} \frac{1}{2} \text { drm. + calcium gluconate, } 1 \text { dr. } \\
,, & ,, & ,, & , \\
,, & , & \mathbf{3} \text { drm. }\end{array}$ \\
\hline 3 & $\begin{array}{l}\text { 23. } 2.32 \text {. } \\
\text { 29. } 3.32 \text {. } \\
\text { 19. } 4.32 \text {. } \\
\text { 24. } 5.32 \text {. } \\
\text { 7. } 6.32 \text {. } \\
\text { 5. } 7.32 . \\
\text { 6. } 9.32 \text {. } \\
24.10 .32 \text {. }\end{array}$ & $\begin{array}{l}0 \cdot 702 \\
0 \cdot 622 \\
0 \cdot 500 \\
0 \cdot 648 \\
0 \cdot 642 \\
0 \cdot 50 \\
0 \cdot 480 \\
0 \cdot 32\end{array}$ & 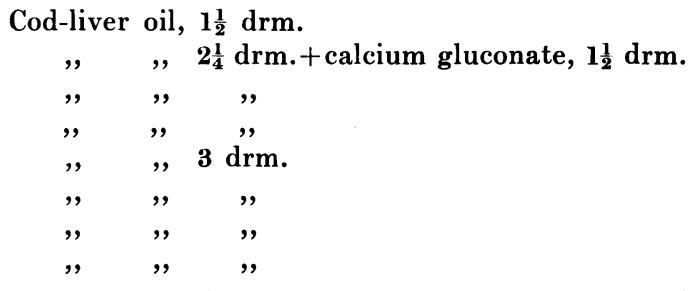 \\
\hline 4 & $\begin{aligned} 24 . & 5.32 \\
\text { 7. } & 6.32 . \\
28 . & 6.32 \\
\text { 15. } & 9.32\end{aligned}$ & $\begin{array}{l}0 \cdot 655 \\
0 \cdot 528 \\
0 \cdot 307 \\
0 \cdot 135\end{array}$ & $\begin{array}{l}\text { Ostelin, } 12 \text { min. + calcium gluconate, } 1 \frac{1}{2} \mathrm{drm} . \\
\text { Cod-liver oil, } 1 \frac{1}{2} \text { drm. } \\
\qquad, ", \quad \text {," } \\
\text {,, } \quad \text { drm. for past } 8 \text { weeks. }\end{array}$ \\
\hline 5 & $\begin{array}{l}\text { 24. } 5.32 \text {. } \\
\text { 13. } 9.32 \text {. }\end{array}$ & $\begin{array}{l}0 \cdot 468 \\
0 \cdot 305\end{array}$ & $\begin{array}{c}\text { Cod-liver oil, } 1 \frac{1}{2} \text { drm. from 2.6.32. } \\
,, \quad,,,\end{array}$ \\
\hline 6 & $\begin{array}{l}\text { 13. } 6.32 . \\
\text { 5. } 7.32 . \\
\text { 7. } 7.32 . \\
6.10 .32 .\end{array}$ & $\begin{array}{l}0 \cdot 51 \\
0 \cdot 312 \\
0 \cdot 35 \\
0 \cdot 33\end{array}$ & 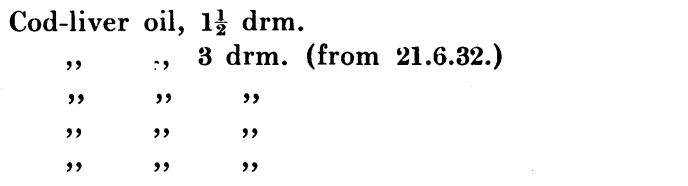 \\
\hline 7 & $\begin{array}{l}\text { 25. } 6.32 . \\
\text { 19. } 7.32 \text {. } \\
\text { 13. } 9.32 \text {. }\end{array}$ & $\begin{array}{l}0 \cdot 669 \\
0 \cdot 294 \\
0 \cdot 33\end{array}$ & $\begin{array}{cc}\text { Adexolin, } & 9 \text { min. } \\
,, & ,, \\
,, & ,,\end{array}$ \\
\hline 8 & $\begin{aligned} \text { 1. } & 3.32 . \\
19 . & 4.32 . \\
\text { 4. } & 6.32 .\end{aligned}$ & $\begin{array}{l}0 \cdot 40 \\
0 \cdot 293 \\
0 \cdot 300\end{array}$ & $\begin{array}{l}\text { Cod-liver oil, } 1 \frac{1}{2} \text { drm. from 8.3.32. } \\
\text { Ostelin, } 9 \text { min. } \\
\qquad, 12,\end{array}$ \\
\hline 9 & $\begin{aligned} 12 . & 7.32 . \\
10 . & 8.32 . \\
6 . & 9.32 . \\
20 . & 9.32 .\end{aligned}$ & $\begin{array}{l}0 \cdot 345 \\
0 \cdot 42 \\
0 \cdot 557 \\
0 \cdot 20\end{array}$ & $\begin{array}{l}\text { No added vitamins } \\
\text { Cod-liver oil, } 1 \frac{1}{2} \text { drm. } \\
\text {,", , , }\end{array}$ \\
\hline 10 & $\begin{aligned} & \text { 17. } 5.32 . \\
& \text { 31. } 5.32 . \\
& \text { 28.6.32. } \\
& \text { 9. } 8.32 . \\
& \text { 13. } 9.32 .\end{aligned}$ & $\begin{array}{l}0 \cdot 3 \\
0 \cdot 36 \\
0 \cdot 420 \\
0 \cdot 33 \\
0 \cdot 219\end{array}$ & $\begin{array}{l}\text { No added vitamins } \\
\text { Cod-liver oil, } \\
\begin{array}{ccc}1 \frac{1}{2} & \text { drm. } \\
\text {,, } & , & , \\
\text {,, } & ,,\end{array}\end{array}$ \\
\hline
\end{tabular}


It would appear, therefore, that assuming other conditions associated with abnormally high plasma phosphatase can be excluded (healing fractures, jaundice), this feature may be taken as an indication that the demands made by growth are excessive. The need is probably variable, the

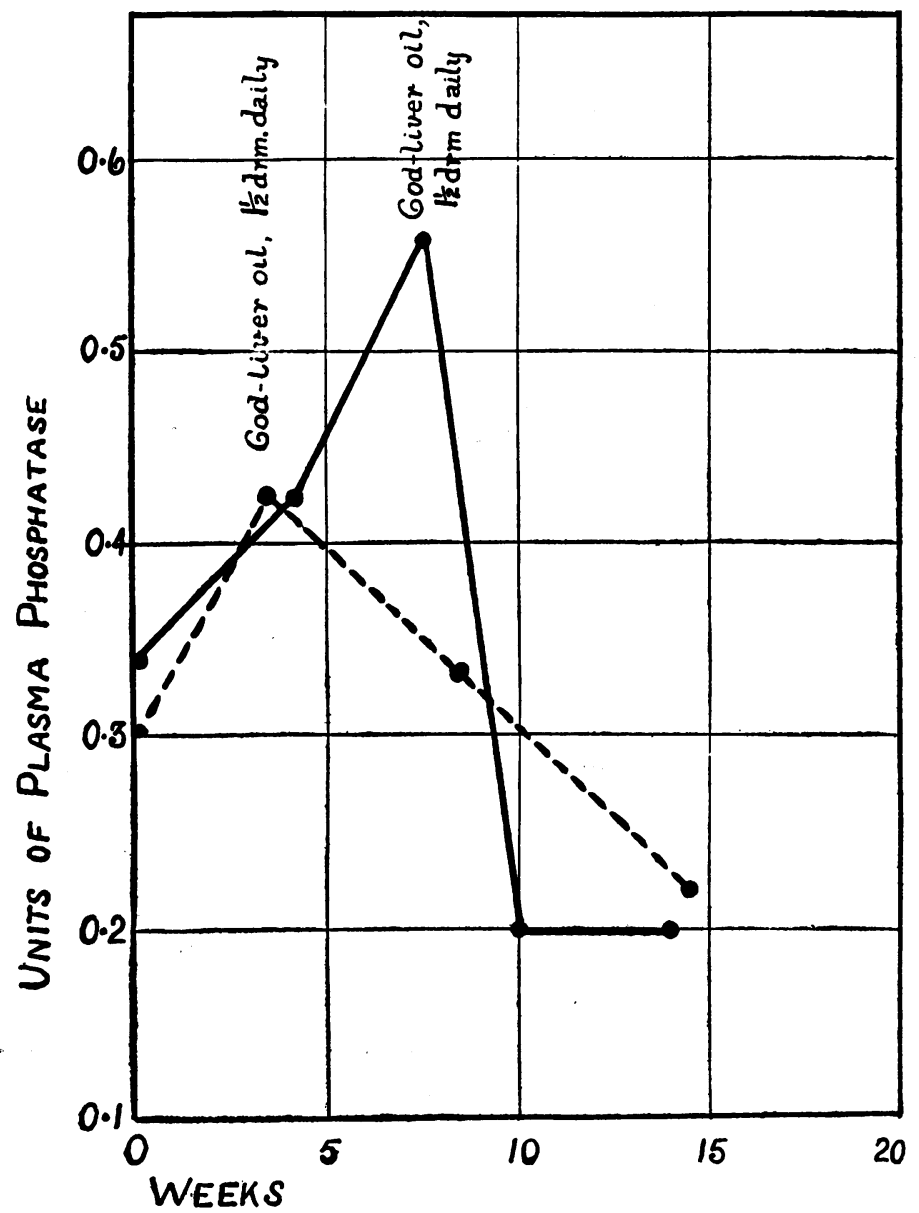

Fig. 2.-Cases 9 and 10 : phosphatase rises as long as fatsoluble vitamins withheld and falls rapidly on administration of cod-liver oil (see Table 1).

amount of fat-soluble vitamin required for perfect bony growth depending on the rapidity of the growth of the child. It has long been recognized that the child who develops rickets is the rapidly growing child whose diet contains insufficient fat-soluble vitamins, or the child who does not make use of them (as in coliac disease) and yet continues to grow.

Plasma phosphatase in retarded growth.-For the purpose of comparison with the above results, estimations of the plasma phosphatase were made in a further group of infants, each of whom showed complete cessation of growth, 
Group 5.-This group included 8 cases of scurvy, 3 of severe marasmus, 2 of cœliac disease, 1 of achondroplasia, and 1 of cretinism. Their ages varied from 4 months to $2 \frac{1}{4}$ years.

The average value for the plasma phosphatase in this group was 0.143 units, with a range of from $0 \cdot 108$ to $0 \cdot 192$ units. The estimations on the cases of scurvy were made immediately on admission, and in the case of two of them with sub-periosteal hæmorrhages, before any calcification had taken place. This process has been shown elsewhere to be associated with a rise in the plasma phosphatase.

Plasma phosphatase as a criterion of rickets.-Park ${ }^{2}$ has pointed out that readings of the serum calcium and phosphorus are not true criteria of the presence or absence of rickets unless the rate of growth is also taken into account. This is because the occurrence of rickets depends on a disturbance of the ratio between the rate of growth and the amounts of serum calcium and phosphorus. Moreover, the institution of anti-rachitic treatment causes a rapid return of the calcium and phosphorus values to normal. This occurs several weeks before the bones appear normal by radiography, in itself but a crude test of bony changes.

These facts prove that estimations of the serum calcium and phosphorus are of no great value as a test for the presence or absence of rickets; and it is probable that the plasma phosphatase is a much more sensitive and accurate index of abnormal bone metabolism in this disease.

\section{Conclusions.}

(1) The average plasma phosphatase of 10 normal breast-fed healthy infants was found to be 0.248 units with a range of from 0.20 to 0.3 units.

(2) The plasma phosphatase of a group of healthy infants fed on artificial foods, but with additional fat-soluble vitamins $\mathbf{A}$ and $\mathbf{D}$ and with water-soluble $\mathrm{C}$, ranged from 0.20 to 0.36 units, with a mean value of 0.30 units, i.e., approximately the same as that of healthy breast-fed infants.

(3) The plasma phosphatase is increased in active rickets. In a group of 16 cases of radiological rickets the figures varied from 0.41 to 1.29 units with an average of $0 \cdot 772$ units.

(4) In a series of infants fed on artificial foods but not receiving extra fat-soluble vitamins, the average plasma phosphatase was 0.52 units with a range of 0.40 to 0.702 units. As long as these vitamins were withheld the plasma phosphatase increased, and when these were added the values fell to within normal limits.

(5) Conditions characterized by cessation of growth, such as cretinism, scurvy and achondroplasia, are associated with an abnormally low plasma phosphatase.

(6) All infants fed on artificial foods should be given additional fat-soluble vitamins within a few weeks of birth.

I wish to thank Dr. Eric Pritchard, the Medical Director and the Staff of the Infants Hospital for facilities given for this work and permission to investigate cases under their care, and Professor Robison for his kind interest in the preparation of this paper.

\section{REFERENCES.}

1. Smith, J., \& Maizels, M., Arch. Dis. Childh., Lond., 1932, VII, 149.

2. Park, E. A., Can. Med. Ass. J., Montreal, 1932, XXVI, 3, 